\title{
O TRABALHO PUBLICITÁRIO: UMA JAM SESSION. IMPROVISO NA CRIAÇÃO E COTIDIANO COM POUCAS VARIAÇÕES
}

\section{THE WORK OF ADVERTISING: A JAM SESSION. IMPROMPTU IN CREATION AND \\ EVERYDAY LIFE IN FEW VARIATIONS}

Edição v.35 número 3 / 2016-17

Contracampo e-ISSN 2238-2577 Niterói (RJ), v. 35, n. 3

dez/2016-mar/2017

A Revista Contracampo é uma revista eletrônica do Programa de Pós-Graduação em Comunicação da Universidade Federal Fluminense e tem como objetivo contribuir para a reflexão crítica em torno do campo midiático, atuando como espaço de circulação da pesquisa e do pensamento acadêmico.

\section{JOÃO ANZANELLO CARRASCOZA}

Mestre e doutor pela Escola de Comunicações e Artes da USP, onde atua como professor. Também é docente no Programa de Pós-Graduação em Comunicação e Práticas de Consumo da ESPM São Paulo, com pós-doutorado na Universidade Federal do Rio de Janeiro. Investiga as narrativas do consumo e a literatura. Ficcionista, recebeu os prêmios literários Jabuti, Guimarães Rosa, Fundação Biblioteca Nacional e APCA, entre outros.

jcarrascoza@espm.br

\section{PPG $\mid C O M$}

AO CITAR ESTE ARTIGO, UTILIZE A SEGUINTE REFERÊNCIA:

CARRASCOZA, João Anzanello. O trabalho publicitário: uma jam session. Improviso na criação e cotidiano com poucas variações.

Contracampo, Niterói, v. 35, n. 03, dez. 2016/ mar. 2017.

Enviado em 11 de setembro de 2015 / Aceito em: 11 de abril de 2016.

DOI: http: //dx.doi.org/10.20505/contracampo.v35i3.875

1- Este artigo faz parte da pesquisa "Consumo e o ensino da publicidade por meio de obras literárias", patrocinada pelo CAEPM. 


\section{Resumo}

O trabalho publicitário vem passando por diversas transformações em virtude especialmente da presença de artefatos tecnológicos em seu dia a dia. A rotina dos profissionais de Criação, o seu processo criativo e certas peculiaridades laborais desta atividade, contudo, não se alteraram plenamente - preservam uma estrutura, senão inflexível, ainda rígida. Por meio de uma retextualização (Bettetini) - método que consiste em transpor textos de um domínio (o literário, por exemplo) para outro (o científico, neste caso) -, vamos investigar aspectos do trabalho publicitário por meio do conto $A$ soneca de Gretchen, de F. Scott Fitzgerald. Teorias sobre o processo de criação em geral e artística, crítica genética e elementos da gestão corporativa serão mobilizados em tal percurso.

Palavras-chave

Trabalho; Literatura; Criação Publicitária

\section{Abstract}

The work of advertising has been experiencing diverse transformations especially in virtue of the presence of technological artefacts in its daily life. However the Creation professionals' routine, their creative process and certain working peculiarities of this activity did not fully modify themselves - they preserve a structure, if not inflexible, but still rigid. By means of a recontextualisation (Bettetini) - a method which consists in transposing texts of one domain (the literary one, for example) to another one (the scientific one, in this case) -, we will investigate some aspects of the work of advertising by means of F. Scott Fitzgerald's tale "Gretchen's Forty Winks". Theories on the creation process in general and on the artistic creation, on genetic criticism and on elements of the corporate management will be mobilised in this route.

\section{Keywords}

Work; Literature; Advertising Creation 


\section{Improviso, jam session e criação publicitária}

O discurso publicitário, independentemente dos meios de comunicação nos quais se espraia, expressa valores das marcas anunciantes que, por meio das mais variadas estratégias de produção discursiva, visam sensibilizar o público para seus atributos corporativos e/ou para as qualidades de seus produtos e serviços.

Se, de um lado, nem sempre esse mesmo público consome materialmente aquilo que as marcas lançam no mercado, por outro, em virtude da extensão atual do sistema midiático, ampliado pela ubiquidade do universo digital, é impossível que não esteja consumindo largamente o discurso de tais marcas. Rocha (1990, p.27) afirma que "se compararmos o fenômeno do 'consumo' de anúncios e o de produtos, iremos perceber que o volume de 'consumo' implicado no primeiro é infinitamente superior ao do segundo".

Daí a importância de conhecer o modus operandi dos profissionais que criam os materiais publicitários (e a natureza de seu ofício), posto que são eles quem delimitam o "modo de ver" da publicidade - atividade, conforme Berger (1975), comparável a um "sistema filosófico", por promover uma visão particular do mundo.

Em seu já clássico livro Magia e capitalismo - Um estudo antropológico da publicidade, Rocha (1990, p.50) aponta que, para os próprios publicitários, "o conhecimento em publicidade se aproxima, por um lado, da noção de 'ciência' e, por outro, da noção de 'arte'". E Ramos (1985), um dos primeiros a escrever sobre a história da propaganda no Brasil, lembra-nos que a arte foi uma das matrizes da publicidade: como tal ofício surgiu no âmbito da mídia impressa, poetas e escritores foram os primeiros produtores de textos publicitários, bem como os pintores e artistas plásticos aqueles que cuidaram, inicialmente, da instância visual dos cartazes e anúncios feitos para promover bens de serviço.

Assim, o processo criativo publicitário incorpora, desde sua origem, procedimentos das artes em geral. E o trabalho artístico, 
seja qual for, sempre conta com o improviso, gesto que é capaz de surpreender, no ato da criação, as linhas de forças acenadas em sua prévia preparação. O improviso é, inesperadamente, o que emerge na própria ocasião do fazer, como numa jam session.

De acordo com Carrascoza (2008), o método criativo na publicidade se dá por meio de bricolagem, ou seja, a utilização de materiais que os criadores têm à mão, e o improviso é um dos elementos que entram nessa composição. Apesar do trabalho publicitário ser "guiado" pelas informações do briefing - conjunto de informações que pautam a criação -, o inesperado, o repentino, faz parte de seus passos. Ou, como enunciou o poeta Mallarmé (1991, p.149): "um lance de dados jamais abolirá o acaso".

Em Criatividade e processos de criação, Ostrower (1978) afirma que as matérias escolhidas pelo artista trazem possibilidades e impossibilidades, sendo, a um só tempo, limitadoras e orientadoras do curso criativo. Em outra obra, este autor discute longamente a ação do acaso no processo de criação artística (OSTROWER, 2001). E Cecília Almeida Salles, em Gesto inacabado, nos lembra que

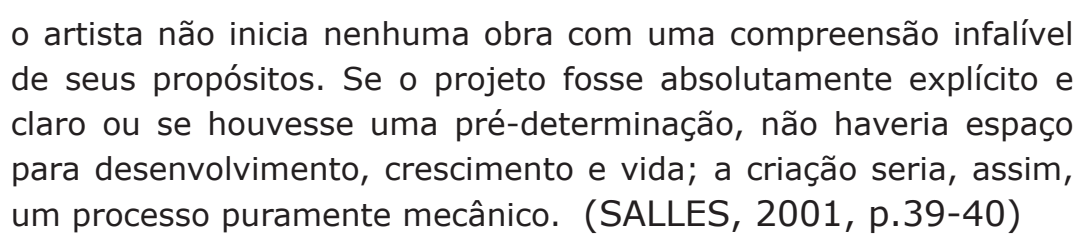

A qualquer momento, ao longo dessa expansão, em parte determinada pelas matérias que o criador põe em jogo, o acaso tem chances de se infiltrar.

O trabalho publicitário, podemos dizer, é regido, igualmente, pelos elementos que vão se definindo durante o processo de bricolagem, no qual o inesperado também é uma variante. Variante contínua, afeita à repetição, como a linha melódica do jazz. A rotina de uma equipe de criação publicitária pode ser comparada, por conta de certa improvisação, a uma jam session. E, assim sendo, buscamos na obra de F. Scott Fitzgerald, o "escritor da Era do Jazz", porta-voz dos fabulous twenties, uma história que nos permitiria abordar alguns aspectos da 
atividade laboral nas agências de publicidade - e, então, chegamos até A soneca de Gretchen.

Com esta história de Fitzgerald, vamos proceder a uma retextualização - método que, segundo Bettetini (1996), ao estudar as interações audiovisuais, permite transpor para um determinado campo de conhecimento (o científico) textos de um outro domínio (o artístico - precisamente, aqui, a literatura).

Noutras palavras, vamos "reler" o conto A soneca de Gretchen com o objetivo de discutir certos aspectos do cotidiano da área de Criação nas agências de propaganda - onde, de fato, o discurso publicitário é "modelado", e como seus profissionais atuam de forma semelhante ao dos artistas. Propomos, portanto, uma abordagem de cunho ensaístico, um extrato similar ao que Paixão (2014), estudando as margens indefinidas do poema em prosa, denomina de "arte da pequena reflexão".

\section{Porque o show publicitário não pode parar}

É noite, o outono havia terminado, as calçadas estavam cobertas de folhas e, certamente, haveria de nevar. Mas Roger Halsey, observando a paisagem lá fora, do alpendre de sua casa, entra logo na sala de estar e acende a luz do hall, pois "não dispunha de tempo para se preocupar com o clima" (FITZGERALD, 2009, p. 255).

Assim se inicia $A$ soneca de Gretchen, e a menção à falta de tempo nos encaminha, sem escalas, para o dia a dia das agências de publicidade, onde há atividades full time e o expediente dos "criativos" costuma ser uma longa jornada noite adentro. Isso porque Roger, logo em seguida, chama Gretchen, com quem está casado há três anos e tem um filho pequeno, para informá-la sobre um fato novo em seu trabalho. Há seis meses ele deixara a Companhia Litográfica de Nova York e começara, por conta própria, a trabalhar em publicidade. Como se não bastasse a mudança, que reduzira a renda da família, Roger anuncia, esperançosamente, para a mulher, que enfrentará um período 
maior e intensivo de trabalho:

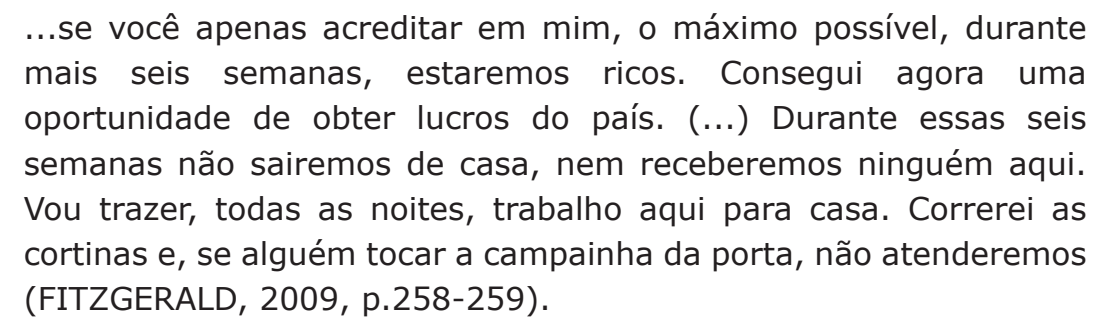

Três aspectos, estreitamente relacionados ao dia a dia publicitário, avultam dessa situação que abre o conto: 1 ) o ingresso de jovens nesse mercado profissional, atraídos pela ideia de ganhos rápidos e vultosos ("se você apenas acreditar em mim... durante mais seis semanas, estaremos ricos"); 2) o prolongamento de seu expediente ("vou trazer, todas as noites, trabalho aqui para casa") e 3) o impacto dessa nova rotina na esfera afetiva, daí porque Roger se põe a prevenir a mulher ("não sairemos de casa", "não receberemos ninguém aqui").

Vejamos cada um desses pontos, começando por essa mística, anunciada e reforçada pelos próprios publicitários - talvez como forma de atrair talentos das novas gerações para a sua arena -, de que os publicitários ganham altos salários, mesmo que sejam meros funcionários de agências, e os empresários desse setor, não importa qual for o seu porte, mais dia menos dias se locupletam, até se tornarem milionários.

Rocha (1990), em sua etnografia com um grupo de publicitários, nos mostra que essa não é senão uma "imagem" de si que eles mesmos constroem, discursivamente, para divulgar à sociedade. Contribuem para reforçar essa "crença", como apontado por Carrascoza (2011), os relatos autobiográficos de grandes nomes da publicidade nacional e internacional, como o clássico Confissões de um publicitário, de David Ogilvy, e Algumas coisas que aprendi em propaganda investindo 1 bilhão de dólares de grandes empresas, do brasileiro Julio Ribeiro, entre outros.

O eco dessa percepção distorcida continua a reverberar: criteriosa pesquisa feita com estudantes de publicidade e propaganda de diversas universidades brasileiras (CASAQUI, RIEGEL e BUDAG, 2011) aponta 
que os aspirantes à profissão identificam o publicitário com determinado estilo de vida que demarca suas diferenças em relação a outros, ou, em outras palavras, um estilo de vida que Ihe dá distinção. Ainda na visão desses estudantes, o ofício publicitário está associado ao sucesso profissional e aos prêmios concedidos pelos agentes do mercado. Mas, para ingressar na profissão, e galgar a glória, eles estão predispostos a enfrentar longas horas de trabalho - com retornos financeiros baixos, pelo menos inicialmente.

Esse é outro traço representativo da atividade do publicitário - o início penoso como pré-condição para que ele alcance, invariavelmente, no futuro, os altos-salários "garantidos" pelo campo. O subtítulo de Cartas a um jovem publicitário, obra de um importante advertising man brasileiro, Roberto Duailibi, sintetiza a presença desse binômio: "Nem tudo é festa. Como vencer na vida fazendo muita força!" É preciso muita força para atuar em publicidade, pois nem tudo é festa, mas, por outro lado, não há como não vencer - é uma carreira já, por si só, de sucesso.

A pesquisa de Paulino (2011, p. 85-86), sobre o perfil socioeconômico dos profissionais de uma grande agência de publicidade nacional, demonstra, pelo nível e faixas de salário apurados, que os altos valores são mais uma "lenda" do que uma realidade cotidiana. E que nem sempre os ganhos maiores estão associados a um tempo maior de trabalho na empresa.

O segundo aspecto em questão, que o conto de Fitzgerald nos permite focar, é não apenas a longa, mas também elástica, jornada de trabalho dos publicitários. Não é incomum que esses, como Roger Halsey, levem trabalho para terminar em casa, ou, o que é mais opressivo, se mantenham na empresa até altas horas da noite, quando não atravessam madrugadas elaborando e/ou finalizando campanhas.

Esse antigo "costume", de "obrigar" o funcionário - com a conivência dele -, a permanecer na agência até que os jobs tenham sido plenamente realizados, agravou-se nos últimos tempos com a aceleração do ritmo laboral pelos novos artefatos tecnológicos: 
As tecnologias suprimiram os intervalos, o deadline aumentou ao ocupar os intervalos que propiciavam ao profissional respirar, distanciar-se; estabelecer rotinas mais compassadas. Esse ganho de tempo já foi consumido e perdido pelo acréscimo e volume gigantesco de trabalho que se assumiu a partir de então (PAULINO, 2011, p. 105).

Duailibi (2006, p.100) afirma que "nada faz as agências perderem tantos seus clientes quanto o não-cumprimento de prazos". $E$, obviamente, a pressão recai sobre os funcionários que, se no passado gozavam de alguma pausa para catalisar seu processo criativo, agora enfrentam a naturalização não apenas das horas extras, mas também do tempo reduzido para maturar as suas ideias. Como, então, proceder à "materialização do sensível" diante dessa progressiva escassez temporal? Salles argumenta que

limites internos ou externos à obra oferecem resistência à liberdade do artista. No entanto, essas limitações revelam-se, muitas vezes, como propulsoras da criação. O artista é incitado a vencer os limites estabelecidos por ele mesmo ou por fatores externos, como data de entrega, orçamento ou delimitação de espaço (SALLES, 2001, p.64).

A utilização crescente de ready-mades em peças publicitárias - de textos ou imagens já prontos, deslocados para a moldura da publicidade -, como investigado por Carrascoza (2008), pode ser uma das consequências do estreitamento do "ócio criativo". É outra solução advinda do improviso e, com essa nova "lei", a jam session também muda de ritmo - afinal, o show da publicidade não pode parar.

Assim, com menos tempo para encontrar soluções, os profissionais de Criação apelam para o emprego de enunciados verbais e/ou visuais já conhecidos, que exigem uma adaptação, ainda que criativa, mas não toda uma criação a partir de elementos difusos, como costuma ser o início, o disparo protoplasmástico, do processo. O anúncio da Apple (fig. 1), elaborado com ready-made, exemplifica com precisão esse estratagema, que se tornou um método criativo intensamente utilizado pelos publicitários. 


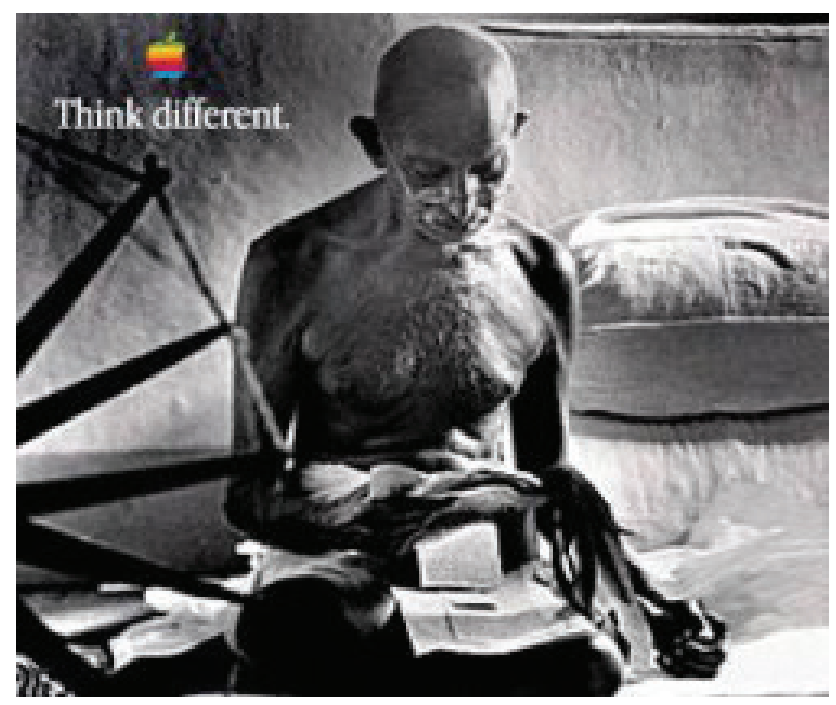

Figura 1: Anúncio Apple. Fonte: http://allthingsd.com/20091002/gandhis-headstarring-as-the-g-in-google/

O mesmo podemos dizer dos anúncios da 3M (fig. 2) e do Delas, canal feminino do IG (fig. 3), que se valem da célebre foto de Che Guevara.

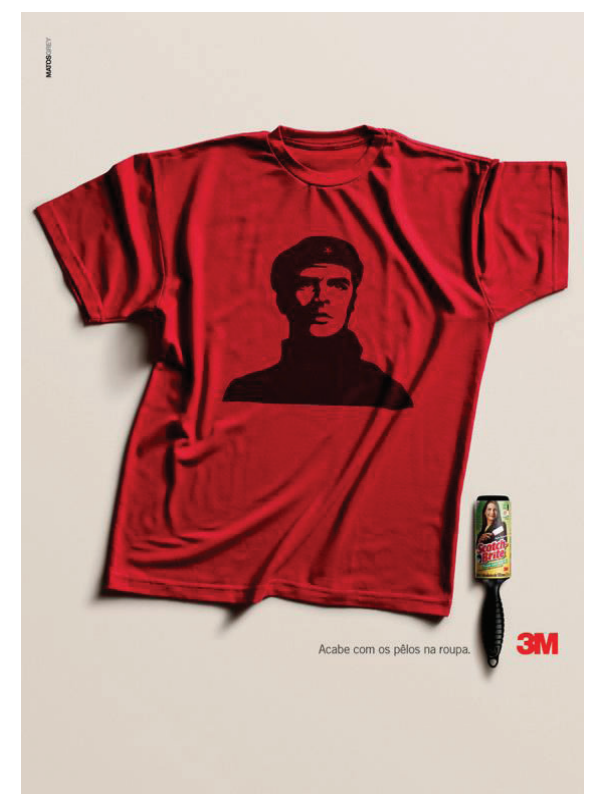

Figura 2: Anúncio 3M. Fonte: http://www.cabecadecuia.com/drops/22969/anunciomostra-che-gevara-sem-barba 


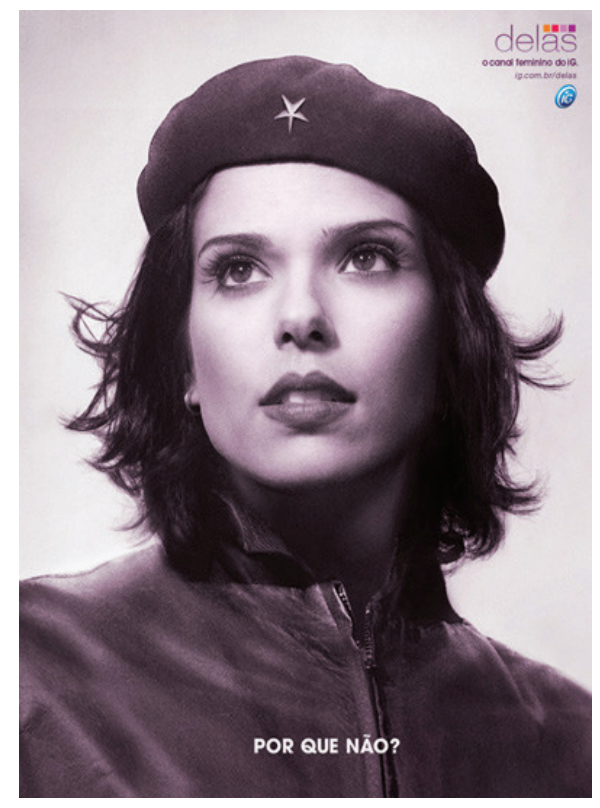

Figura 3: Anúncio Delas IG. Fonte: http://www.designergh.com.br/2013/02/porque-nao.html

Contudo, o ready-made, não obstante seja uma alternativa expressiva para algumas peças de publicidade, não o é para todas. $\mathrm{E}$ o desafio de encontrar saídas criativas em tempo exíguo, somado a outros, resulta, para os profissionais, na submissão a um clima diário - nunca aliviado - de tensão.

Nesse contexto, de ininterrupta tensão, o estresse também é contínuo. Como diagnostica Paulino (2011, p.109) em sua pesquisa, as relações de trabalho contemporâneas na publicidade se tornaram mais competitivas - ampliando a concorrência entre os profissionais e acentuando a falta de camaradagem. Fator que gera comportamentos nem sempre éticos, já relatados por Della Femina (2011) em Mad Men, e que deságua no terceiro aspecto que o conto de Fitzgerald, aqui retextualizado, nos leva a discutir: o esgarçamento geral dos afetos, especialmente no núcleo familiar.

Ainda que a erosão dos laços humanos duradouros, e a ascensão das relações efêmeras em virtude da líquida racionalidade moderna, como argumenta Bauman em Amor líquido (2004), não seja prerrogativa dos vínculos próprios ao mundo publicitário, ela se manifesta de forma vigorosa nas tribos de white collars, executivos de comunicação e 
adverstising men.

Se falta tempo para o publicitário criar, em virtude da volumosa carga de trabalho, dos prazos apertados e das pausas que rarearam, além do prolongamento da jornada, como manter engajamentos afetivos permanentes? Bauman (2004, p. 65) alerta que a razão líquida "nega direito aos vínculos e liames, espaciais ou temporais", sem contar que os relacionamentos de longa data são vistos como opressão ou dependência incapacitante. Para o sociólogo, metaforizando as uniões transitórias e as de laços fortes, o que prevalece é a primazia dos "mantos leves" e a condenação das "caixas de aço".

Podemos notar com clareza o início desse conflito afetivo, que advém da esmagadora rotina laboral, em A soneca de Gretchen, logo depois do publicitário se entregar ao novo ritmo de trabalho:

\footnotetext{
Das oito da manhã até às cinco e meia da tarde, ficava em seu escritório. Depois, meia hora no trem suburbano, onde garatujava anotações no verso de envelopes sob a luz fosca e amarelada. Às sete e trinta, seus creions, tesouras e folhas de cartolina branca eram estendidos sobre a mesa do living, e lá ficava a trabalhar, em meio de muitos resmungos e suspiros, até meia-noite, enquanto Gretchen permanecia deitada no sofá com um livro (...) À meianoite, havia sempre uma discussão sobre se ele iria ou não para a cama (FITZGERALD, 2009, p.263).
}

Em verdade, na mesma noite que Roger anuncia à mulher que vai trazer trabalho para casa nas próximas quarenta noites - "Tire quarenta sonecas e, quando despertar, tudo estará ótimo", ele Ihe diz -, e antes de se lançar a esse desafio, o casal já tem uma primeira discussão, pois foram convidados a jantar por um amigo do marido, George Tompkins, e divergem se devem ou não aceitar. Por fim, Roger e Gretchen acabam decidindo ir à casa de George, que, veremos, tentará dinamitar a "caixa de aço", até então, do casamento dos Halseys.

No encontro do casal com o amigo, ficam evidentes as diferenças em relação ao estilo de vida dos dois homens: George faz exercícios físicos pela manhã (mantém em sua própria casa uma espécie de academia), cumpre uma jornada de trabalho apenas até as quatro horas e, invariavelmente, daí em diante, pratica algum esporte, condizente com a estação do ano, para relaxar, e, depois, sempre tem 
um programa ("faço alguma coisa, todas as noites, para ver-me livre de mim"). Já Roger não tem tempo para cuidar de sua forma física, acorda cedo e segue direto para o escritório, onde, ultimamente, vem trabalhando até aos domingos.

Quando George faz a descrição de sua rotina, Roger, cansado, boceja, e Gretchen o repreende, contando ao anfitrião que, nas próximas semanas, o marido continuará o trabalho noite adentro. George alerta o amigo, aquele tempo é suficiente para colocá-lo a caminho do sanatório, e, com um sorriso para Gretchen, diz, a fim de agradá-la: "A mim me parece que é sobre a esposa, mais do que sobre o marido, que recai todo o peso desses períodos malucos de excesso de trabalho" (FITZGERALD, 2009, p.261).

A noite, contudo, termina numa atmosfera de "harmonia" para 0 casal Halsey: Roger se irritou de fato com o amigo, Gretchen ficou ao seu lado, mas não deixou de pensar no convite que George Tompkins Ihe fizera no fim do jantar - passear com ele a cavalo no domingo próximo.

Nas semanas seguintes, conforme anunciara, Roger se lançou àquela nova rotina. Todas as noites, ao subir a escada de casa na ponta dos pés para dormir, encontrava Gretchen já em sono profundo. O Natal chegara e se fora, ele nem percebera o tempo passar, estava enfiado até os ossos no trabalho que, pelos seus cálculos, se metade de suas ideias vingasse, garantiria grandes lucros ao longo do ano novo. Mantinha-se tão concentrado em seu desafio que, para ele, "o mundo se convertera num sonho caótico", mas, ainda assim, não ignorava que

George Tompkins levara Gretchen a passear a cavalo, e que em outra ocasião ela saíra com ele de automóvel e passara a tarde a esquiar na colina do clube de campo. Um retrato de Tompkins, numa moldura cara, apareceu, uma manhã, na parede de seu quarto de dormir. E, certa noite, ele, escandalizado, se entregou a sobressaltado protesto, quando Gretchen saiu para ir ao teatro em companhia de Tompkins (FITZGERALD, 2009, p.263-4).

Com seu tempo monopolizado pelo trabalho, a convivência afetiva de Roger com a mulher se reduz, acelerando o processo de derretimento da "caixa de aço" do casamento dos Halseys, cujo 
fogo abrasivo George acendeu e mantém alto ao "cortejar" a esposa "abandonada" do amigo.

Como se não bastasse, embora Roger já estivesse terminando os jobs, sua saúde pede cuidados, ele é obrigado a renunciar ao café, que está Ihe causando palpitações; e um desentendimento com Gretchen, iniciado por um comentário dela sobre as contas de dezembro que não tinham como pagar, aprofunda-se quando ela anuncia que convidara George Tompkins para visitá-los àquela noite.

Impedido de "fazer sala" para o amigo, Roger, contrariado, o deixa na companhia de Gretchen e sobe para a trabalhar lá em cima. Mas aquela situação o perturba e, depois de uma hora, ele percebe que não produziu nada e retorna à sala, onde encontra a mulher e o amigo conversando sobre a "sua" saúde.

Uma discussão se origina, então, entre ele e George, quando esse busca "desqualificar" o fazer publicitário - assunto que vamos tratar a seguir, já que as tendências de um projeto vão se definindo ao longo do percurso (SALLES, 2001, p.40), assim como as notas numa jam session -, e o conflito se intensifica a ponto de Roger expulsar o amigo dali e continuar a "guerra" com Gretchen, que toma o partido do outro. Ela protesta, com os olhos cheios de lágrimas de ódio: "o único amigo que tenho, a única pessoa no mundo que gosta de mim o bastante para me tratar decentemente, é insultado pelo meu próprio marido, em minha própria casa" (FITZGERALD, 2009, p.268).

\section{Publicitários: artistas da razão ou mad men?}

Antes disso, na noite em que convidara os amigos para jantar em sua casa, George, que é um decorador de interiores de sucesso, já fizera uma crítica ao tipo de trabalho de Roger, precisamente ao seu longo expediente: "você vai acabar por se matar de tanto trabalhar. Por que não estabelece um pouco de equilíbrio em sua vida... um pouco de trabalho, um pouco de distração" (FITZGERALD, 2009, p.259).

Mas, dessa vez, na casa dos Halseys, seu ataque vai direto na essência da atividade publicitária, que consome o tempo (e a vida) dos 
criativos como Roger, e ainda resulta numa obra desprezível. George diz que Roger pensa de forma egoísta, esquecendo-se de dar atenção à mulher:

\begin{abstract}
Se você estivesse trabalhando em algum soneto maravilhoso... ou no retrato de alguma Madona ou coisa que o valha - ajuntou, fitando os cabelos à Ticiano de Gretchen -, então, claro, eu Ihe diria que prosseguisse. Mas não está. Trata-se apenas de um anúncio tolo para aumentar as vendas do tônico de cabelo Nobald, e se todos os tônicos capilares fossem amanhã lançados no oceano, o mundo não perderia coisa alguma com isso (FITZGERALD, 2009, p.266).
\end{abstract}

Roger se enfurece com o amigo, já que, de certa forma, George Tompkins atira no colo do amigo uma questão clássica, nodal, que rege o universo publicitário: a publicidade é ou não arte?

Obviamente, a polêmica divide opiniões há décadas, e não será aqui que vamos resolvê-la, nem é o nosso intuito. Mas convém mencionar três aspectos norteadores dessa discussão: 1) a sua eclosão, em virtude da arte ter sido (e continuar sendo) uma matriz da linguagem publicitária, mantendo com ela "relações promíscuas" como se expressou Chillón (1999) acerca da literatura e do jornalismo; 2 ) os procedimentos artísticos presentes no "fazer publicitário e que nutrem o antagonismo de posições"; e 3) o status do "produto" resultante de seu processo, que, para uns, seria uma manifestação artística do século XX, como sustenta Piratininga (1994) e, para outros, como George Tompkins e Toscani (1995), apenas algo tolo.

A valorização ou o desprezo para com o trabalho publicitário e seu fruto enseja, no fundo, uma representação também dual do homo que o executa: ou ele é um "artista" da razão, quer dizer, um criador consciente de que o seu talento deve lhe garantir a sobrevivência, não obstante esteja a serviço de causas corporativas; ou ele é um mad man, que, apesar das muitas instâncias a que a sua criação está submissa (Hansen, 2013), garante o seu salário, enquanto se dedica à "coisa mais divertida que alguém pode fazer vestido", como afirma Olivetto (2004, p.10).

Essa insinuação de que o trabalho publicitário é fonte de prazer, e não só em si, mas também na diversão sexual que propicia, nos remete à 
série de TV americana Mad Men, inspirada na obra de Della Femina. Em suas sucessivas temporadas, os personagens principais, publicitários de uma agência de propaganda de Nova York nos anos 1960, vivem num estado de relações promíscuas, prefigurando, naqueles tempos de "revolução sexual", o "amor líquido". E essa liquidez amorosa não se restringe aos chefes, como o diretor de criação, Don Draper, ou um dos donos da agência (e homem de atendimento) Roger Sterlling, mas se dissemina, como rizoma, pelos demais escalões.

Se o protagonista Don Draper é o exemplo notável desse comportamento, sua mulher, abandonada em casa, não por acaso começa a pensar em traí-lo nas aulas de equitação que faz para ocupar seu tempo e sua solidão - assim como Gretchen, ao atender o convite de George para passear a cavalo.

Assim, o escasso diálogo entre o casal Halsey prova que "o fracasso no relacionamento é muito frequentemente um fracasso na comunicação" (Bauman, 20104, p.31). E isso se sucede, de forma irônica, na esfera de trabalho daqueles que atuam como comunicadores sociais. Curiosamente, a esposa de Don Draper - que, aos poucos, se revela um alcoólatra -, também fica em casa, solitária, bebendo até altas horas, à sua espera, desenvolvendo estranhos comportamentos, como Zelda, mulher de Fitzgerald.

Mas, no cerne da percepção de George sobre o labor publicitário de Roger, está, indiscutivelmente, o dilema angustiante dos criativos: se, de um lado se conformam com a imagem periférica de seu trabalho na sociedade - daí porque, em seu próprio campo, vivem a se exibir -, por outro, não raro buscam produzir uma obra autoral, dedicando-se, em paralelo, à literatura, às artes plásticas, ao cinema, atividades para as quais, é óbvio, Ihes falta tempo para tirá-las do papel, como no caso de Roger.

Della Femina (2011, p.135) aborda, sem "panos leves", esse problema de reconhecimento que aflige os criativos, focando nos redatores, mas a observação vale também para os diretores de arte: 
Há um monte de redatores que fica achando que é o Faulkner ou o Hemingway. (...) As pessoas não compram a Gourmet para ler o anúncio sobre o Bombay Gin. As pessoas compram a Gourmet por causa das receitas culinárias, os anúncios são apenas um sequestro do tempo do leitor (...) Ninguém compra uma revista para ler um anúncio. Mas um monte de caras age como se fosse isso o que acontecesse.

A falta do reconhecimento artístico de suas criações, ou de certo reconhecimento restrito às medidas e referenciais pragmáticos do campo, é talvez a raiz do famigerado exibicionismo dos publicitários: se estão deslegitimados, à sombra da "alta" cultura, precisam febrilmente, em seu palco, dos mais potentes holofotes.

Na citação acima, de Della Femina, insinuam-se dois outros problemas associados a esse tipo de trabalho: 1) a publicidade opera por meio de uma lógica da interrupção ("As pessoas não compram a Gourmet para ler o anúncio sobre o Bombay Gin") e 2) também por meio de uma lógica (disfarçada) de invasão ("os anúncios são apenas um sequestro do tempo do leitor").

O desprezo de George para com a atividade profissional de Roger - um anúncio do tônico de cabelo Nobald, ou do Bombay Gin, não é nada, do ponto de vista artístico - intensifica o conflito entre a visão de mundo do publicitário e do não-publicitário. E, como mencionamos, Roger acaba por expulsar o amigo de casa. Gretchen, em reação vingativa diz "vou passear a cavalo, amanhã, em companhia de George Tompkins" e ameaça o marido: "gostaria de apanhar todo o trabalho que você fez, rasgá-lo em pedaços e atirá-lo ao fogo" (FITZGERALD, 2009, p.268-9).

Roger, no entanto, continua trabalhando naquela noite até alta madrugada - tem obrigatoriamente de cumprir prazo. E, numa tentativa derradeira de manter ainda inviolável a "caixa de aço" de seu relacionamento conjugal, no dia seguinte, antes de ir ao escritório, coloca um sonífero na xícara de café de Gretchen, corta o fio do telefone da casa e leva numa bolsa todos os sapatos da mulher, para impedi-la de se encontrar com George Tompkins.

Em seu escritório, Roger é cobrado pelo senhorio, o pagamento 
do aluguel está em atraso. O publicitário atravessa o dia "criando" e adormece lá mesmo, num sofá ao lado da mesa. Aguarda, ansiosamente, na manhã seguinte, por uma ligação de Garrod, um dos clientes de que esperava Ihe dar grandes lucros. E, quando Garrod de fato telefona, aprovando o material - e dizendo "é maravilhoso o trabalho que nos enviou. Queremos tudo o que nos mandou e muito mais, à medida que o seu escritório os puder ir produzindo" (FITZGERALD, 2009, p.274) -, Roger quase sofre um ataque cardíaco, tal a intensidade de sua catarse.

A boa notícia é um prêmio pela sua entrega ao trabalho, mas um prêmio que, se resulta em dinheiro, resulta também em mais trabalho, mais noites em claro, perpetuando uma corrente inquebrável de "exploração" que conta com a concordância não só do "senhor", mas também do próprio "escravo". Acordes que se repetem, com alguma variação, como numa jam session.

\section{Notas finais}

Ao chegar em casa para contar a novidade, Roger encontra Gretchen, que acaba de despertar, ainda arrependida da discussão que travara com o marido. Embora feliz com o contrato de quarenta mil dólares que Roger fechou com Garrod, com os vestidos novos que ela poderá comprar, Gretchen se sente confusa, dormiu duas noites seguidas - é o efeito da droga que bebeu misturada ao café -, não encontra seus sapatos, está pálida e amedrontada com seu estado.

Arrependido, Roger, sabe que é o causador do problema, e resolve chamar um médico. Então, o desenlace da história se concretiza de forma "disfórica". O médico recomenda somente repouso à Gretchen. "Se ela ficar em casa durante alguns dias e tirar umas boas sonecas, ficará logo em forma" (FITZGERALD, 2009, p.277), prescreve o doutor, sem imaginar que, nos últimos quarenta dias, ela não fez mais do que tirar sonecas, enquanto Roger trabalhava dia a dia quase sem dormir.

Aliás, por meio desse médico, o casal saberá que George 
Tompkins, com quem Gretchen iria sair para passear, teve uma crise nervosa, apesar de seu "estilo de vida" oposto ao de Roger.

Atingimos, assim, o final de nossa retextualização, ressaltando que os personagens deste conto de Fitzgerald, por analogia, representam forças atuantes, e resistentes, na esfera do trabalho publicitário. Sua presença nos permitiu - e nos permite - pensar no expediente intenso dos profissionais de Criação, cercados na atualidade por muita tecnologia e, não obstante, como revela a pesquisa de Paulino (2011, p.88), cientes de que seu trabalho está essencialmente vinculado às relações interpessoais.

Neste contexto, e seguindo as conclusões de Paulino (2011), notamos que as mudanças no mundo do trabalho publicitário resultaram estruturalmente em poucas variações, uma vez que nele prevalece a forte concorrência entre os colegas (como a de Roger e George, ainda em que de outro gênero), as jornadas de trabalho extensas (iguais as de Roger) e o ritmo acelerado (como o de George), que colaboram inegavelmente para a tensão e o estresse dos profissionais dessa área.

Falta, sobretudo, aos "criativos", nas palavras de Paulino (2011, p. 109), "abertura para o acesso a produções culturais que permitam vislumbrar outros pontos de vista. Visões de mundo diferenciadas". Visões que, para nós, enquanto Gretchen dorme, são negadas aos publicitários pela realidade diária de seu trabalho.

\section{Referências bibliográficas}

BAUMAN, Zygmunt. Amor líquido. Sobre a fragilidade dos laços humanos. Rio de Janeiro: Zahar, 2004.

BERGER, John. Modos de ver. Barcelona: Gustavo Gilli, 1975.

BETTETINI, Gianfranco. La conversación audiovisual. Barcelona: Cátedra, 1996.

CARRASCOZA, João Anzanello. Do caos à criação: processo criativo, plágio e ready-made na publicidade. São Paulo: Saraiva, 2008.

E o vento mudou... As transformações do trabalho 
publicitário. In: CASAQUI, Vander; LIMA, Manolita Correia; RIEGEL, Viviane (orgs.). Trabalho em publicidade e propaganda. História, formação profissional, comunicação e imaginário. São Paulo: Atlas, 2011.

CASAQUI, Vander; LIMA, Manolita Correia; RIEGEL, Viviane (orgs.). Trabalho em publicidade e propaganda. História, formação profissional, comunicação e imaginário. São Paulo: Atlas, 2011.

CHILLÓN, Albert. Literatura y periodismo - Una tradición de relaciones promiscuas. Barcelona: Universitst Autònoma de Barcelona, 1999.

DUAILIBI, Roberto. Cartas a um jovem publicitário. Nem tudo é festa. Como vencer na vida fazendo muita força! Rio de Janeiro: Elsevier, 2006.

FEMINA, Jerry Della. Mad Men. Comunicados do front publicitário. Rio de Janeiro: Record, 2011.

FITZGERALD, F. Scott. Seis contos da era do jazz e outras histórias. Rio de Janeiro: José Olympio, 2009.

FUENTES, Carlos. Eu e os outros - Ensaios escolhidos. Rio de Janeiro: Rocco, 1989.

HANSEN, Fabio. (In)verdades sobre os profissionais de criação: poder, desejo, imaginação e autoria. Porto Alegre: Entremeio, 2013.

KLEE, Paul. Diários. São Paulo: Martins Fontes, 1990.

MALLARMÉ, Stéphane. Um lance de dados jamais abolirá o acaso. In: Campos, Augusto de, Pignatari, Décio e Campos, Haroldo de. Mallarmé. $3^{a}$ ed., São Paulo: Perspectiva, 1991.

OLIVETTO, Washington. Com alguma razão e certa sensibilidade. In: CARRASCOZA, João Anzanello. Razão e sensibilidade no texto publicitário. São Paulo: Saraiva, 2004.

OSTROWER, FAYGA. Criatividade e processos de criação. Petrópolis: Vozes, 1978.

Campus, 1990.

Acasos e criação artística. Rio de Janeiro:

PAIXÃO, Fernando. Arte da pequena reflexão - Poema em prosa contemporâneo. São Paulo: Iluminuras, 2014.

PAULINO, Roseli Aparecida Fígaro. Perfil sociocultural dos comunicadores: conhecendo quem produz a informação publicitária. In: CASAQUI, Vander; LIMA, Manolita Correia; RIEGEL, Viviane (orgs.). Trabalho em publicidade e propaganda. História, formação profissional, comunicação e imaginário. São Paulo: Atlas, 2011.

PIRATININGA, Luiz Celso de. Publicidade: arte ou artifício? São Paulo: T.A.Queiroz, 1994. 
RAMOS, Ricardo. Do reclame à comunicação - Pequena história da propaganda no Brasil. São Paulo: Atual, 1985.

ROCHA, Everardo P. Guimarães. Magia e capitalismo - Um estudo antropológico da publicidade. $2^{a}$. ed. São Paulo: Brasiliense, 1990.

SALLES, Cecilia Almeida. Gesto inacabado: processo de criação artística. $2^{a}$. ed., São Paulo: FAPESP/Annablume: 2001.

TOSCANI, Oliviero. A publicidade é um cadáver que nos sorri. Rio de Janeiro: Ediouro, 1995. 